\title{
COMPOSIÇÃO E DIGESTIBILIDADE PROTEICA DE SUPLEMENTOS ALIMENTÍCIOS CONTENDO PROTEÍNA DE SORO DE LEITE (WHEY PROTEIN)
}

\author{
Composition and protein digestibility of food supplements \\ containing whey protein
}

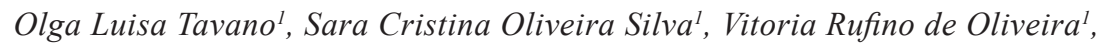
Hudsara Aparecida de Almeida Paula ${ }^{*}$
\end{abstract}

\begin{abstract}
RESUMO
Dentre os suplementos dietéticos, os fabricados com proteína de soro de leite apresentam um excelente perfil aminoacídico e caracterizam-se como proteínas de alto valor biológico. No entanto, como resultado da falta de uniformidade, a qualidade nutricional deste tipo de produto é incerta. Assim, este estudo verificou a composição proteica e digestibilidade in vitro desses produtos. Foram adquiridas 12 amostras de suplementos e o teor de proteínas foi determinado pelo método de Kjeldahl. Para a determinação da digestibilidade proteica in vitro foi adotado a medida do percentual de hidrólise de cada amostra, após tratamento com sequência de enzimas pepsina e pancreatina. Ao comparar a composição proteica com os valores declarados nos rótulos dos produtos comercializados observou-se que a maioria das amostras analisadas estava de acordo com o valor declarado. Quanto a digestibilidade proteica in vitro, constatou-se grandes diferenças entre os resultados das amostras. Os valores encontrados oscilaram entre $24,2 \%$ e $42,2 \%$ e estavam abaixo do valor de hidrólise proteica da caseína $(48,9 \%)$. Esta grande variação pode ser devido às diferentes composições proteicas dos suplementos alimentícios, já que, embora sejam suplementos que trazem em seu rótulo principal o termo whey protein, também veiculam muitas vezes outras proteínas, como proteínas de soja. Além disso, as formulações podem ter em sua composição sucos de frutas ou cacau. Como conclusão, o estudo dos reais teores proteicos, em comparação ao declarado no
\end{abstract}

1 Universidade Federal de Alfenas, Rua Gabriel Monteiro da Silva, 700, Centro, 37130-001, Alfenas, MG, Brasil. E-mail: hudsara.paula@unifal-mg.edu.br

* Autor para correspondência.

Recebido / Received: 21/06/2017

Aprovado / Approved: 08/12/2017 
rótulo, e mesmo o grau de hidrólise alcançado destas formulações, como indicativo de suas digestibilidades, se mostra cada vez mais importante.

Palavras-chave: proteínas de soro de leite; digestibilidade proteica; suplementos.

\begin{abstract}
Among dietary supplements, those made with whey protein have an excellent amino acid profile and are characterized as proteins of high biological value. However, as a result of lack of uniformity, the nutritional quality of this type of product is uncertain. Thus, this study aimed to verify the protein composition and in vitro digestibility of these products. Twelve samples were obtained. The protein content was determined by the Kjeldahl method. To determine the in vitro protein digestibility, the percentage of hydrolysis of each sample was measured after treatment with pepsin and pancreatin enzyme sequence. By comparing the protein composition with the declared values on the labels of products it was observed that most of the samples was in accordance with the declared value. Regarding protein digestibility in vitro, great differences were found between the results of the samples. The values founded ranged from $24.2 \%$ to $42.2 \%$, which were below the casein hydrolysis of $48.9 \%$. This variation may be due to different protein compositions of food supplements, since although they show in their main label the term Whey Protein, often contain other proteins, such as soy proteins. In addition, the formulations may have in their composition fruit juices or cocoa. As a conclusion, the study of the actual protein content, as compared to the one declared on the label, and even the degree of hydrolysis of these formulations, as indicative of their digestibilities, is increasingly important.
\end{abstract}

Keywords: whey protein; protein digestibility; supplements.

\section{INTRODUÇ̃̃̃O}

Segundo a Instrução Normativa $n^{\circ} 16$, de 23 de agosto de 2005, Ministério da Agricultura, Pecuária e Abastecimento, entendese por soro de leite o líquido residual obtido a partir da coagulação do leite destinado à fabricação de queijos ou de caseína (BRASIL, 2005).

Uma vez que a caseína é retirada do meio, a solução residual restante ainda mantém as proteínas solúveis do leite, que apresentam um excelente perfil de aminoácidos e caracterizam-se como proteínas de alto valor biológico. Esta fração solúvel do leite apresenta capacidade de se manterem solução em pH 4,6 e é constituída por um grupo heterogêneo de proteínas, sendo suas maiores frações a $\beta$-lactoglobulina e $\alpha$-lactoalbumina, além de imunoglobulinas, lactoferrinas, soro albumina e outras frações menores (SMITHERS, 2008).

Embora historicamente se tenha registros de sua utilização datados de cerca de 3000 anos atrás, somente nas últimas décadas o soro de leite vem recebendo atenção como componente a ser utilizado na alimentação humana, seja incorporado a diferentes produtos alimentícios, seja como fonte proteica em suplementos destinados às dietas para atletas, conhecido como whey, termo inglês para soro de leite (HARAGUCHI et al., 2006; LACROIX et al., 2006; SMITHERS, 2008). As proteínas presentes no mercado 
de suplementos esportivos são normalmente compostas pelo concentrado proteico do soro (whey protein), um produto com alto valor nutricional cuja concentração de proteínas varia entre $25 \%$ e $89 \%$. Nesses produtos há a remoção dos constituintes não proteicos (LOVATO et al., 2014).

Estes suplementos apresentam um perfil diferenciado de aminoácidos, especialmente constituído de altas concentrações de sulfurados, lisina, triptofano e com destaque para seus teores de aminoácidos de cadeia ramificada, os quais favorecem o anabolismo, assim como a redução do catabolismo proteico, favorecendo o ganho de força muscular e reduzindo a perda de massa muscular durante a perda de peso (HARAGUCHI et al., 2006; LACROIX et al., 2006; SMITHERS, 2008).

Do ponto de vista aminoacídico (aminoácidos essenciais), as proteínas de soro apresentam quase todos os aminoácidos essenciais em excesso às recomendações, sendo altamente digeríveis e rapidamente absorvidos pelo organismo estimulando a síntese de proteínas sanguíneas e teciduais (SGARBIERI, 2004).

Para serem classificadas como suplementos proteicos, as whey protein devem atender aos seguintes requisitos: o produto pronto para consumo deve conter, no mínimo, $10 \mathrm{~g}$ de proteína na porção e conter, no mínimo $50 \%$ do valor energético total proveniente das proteínas, podendo ser adicionado de vitaminas e minerais, sendo proibida a adição de fibras alimentares e de não nutrientes (ANVISA, 2010).

Ainda que o perfil de aminoácidos seja um primeiro parâmetro observado quando se avalia o valor nutricional de uma proteína, sua digestibilidade pode ser de maior importância, já que garante a liberação destes aminoácidos para absorção através dos enterócitos (OSTE, 1991).

No que diz respeito às características estruturais das principais frações proteicas constituintes do soro de leite, estas apresen- tam alto potencial de hidrólise por enzimas digestivas, mas, é importante observar que interações sofridas com componentes do meio podem prejudicar o acesso de proteases aos seus sítios catalíticos, prejudicando o aproveitamento de proteínas da dieta.

Comercialmente são encontradas diferentes formulações contendo proteínas de soro de leite, especialmente no que se refere a dietas para atletas, em que se acrescentam à estas proteínas outros ingredientes e aditivos de sabor, cor e mesmo consistência. Alguns destes compostos podem interferir na digestibilidade das proteínas, como por exemplo, compostos fenólicos, que são conhecidos por reduzirem a digestibilidade de proteínas ao formarem complexos (BRAVO, 1998; RAWEL et al., 2001).

O consumo de proteínas de soro de leite bovino vem aumentando nas últimas décadas, em especial incorporado a produtos destinados a atletas. Muitos destes suplementos são comercializados na forma de misturas de nutrientes em pó contendo outros componentes e/ou apresentando suas proteínas na forma pré-hidrolisada, que agregam valor ao produto. $\mathrm{O}$ estudo dos reais teores proteicos destas formulações, em comparação ao declarado no rótulo, dos reais benefícios destas fórmulas hidrolisadas, ou seja, na melhoria de suas digestibilidades, se mostra importante. Este estudo colabora para esta discussão.

Neste sentido, este trabalho objetivou verificar o teor proteico dos produtos comerciais identificados como suplementos proteicos disponíveis no comercio local de Alfenas-MG, determinando e discutindo sua relação com a digestibilidade proteica destas formulações.

\section{MATERIAL E MÉTODOS}

Foram adquiridas amostras disponíveis no comércio local do município de AlfenasMG, identificados como suplementos proteicos, especialmente destinados às dietas para 
atletas. O teor de proteínas foi determinado pelo método de kjeldahl (AOAC, 1990), utilizando-se o fator 6,25 para conversão de nitrogênio a proteínas. Foram determinadas as digestibilidades proteicas in vitro das amostras, por meio da medida do percentual de hidrólise de cada amostra, após tratamento com sequência de enzimas pepsina e pancreatina, como descrito por Akeson e Stahman (1964).

Para cada amostra foram preparados dois tubos contendo massa equivalente a $25 \mathrm{mg}$ de proteína, sendo um tubo destinado ao ensaio da amostra e o outro ao branco das amostras (sem adição de enzimas). Um outro tubo foi preparado sem qualquer adição de proteína, destinado ao cálculo do branco das enzimas (apenas contendo os tampões e as enzimas).

Em cada tubo foi acrescentado 3,5 ml de tampão $\mathrm{KCl}-\mathrm{HCl}$, pH 1,5 e 4 ml de solução de pepsina $(6,5 \mathrm{mg}$ de pepsina/ml em tampão $\mathrm{KCl}-\mathrm{HCl}, \mathrm{pH} 1,5)$ e $0,25 \mathrm{ml}$ de tampão no caso dos brancos das amostras. Os tubos foram incubados em banho-maria $37{ }^{\circ} \mathrm{C}$ durante três horas.

Após três horas de incubação, foram acrescentados, em cada tubo, $4 \mathrm{ml}$ de tampão fosfato de sódio $0,2 \mathrm{M}, \mathrm{pH} \mathrm{8,0}$ (para neutralização do meio de reação), $40 \mu \mathrm{l}$ de timerosol e $3 \mathrm{ml}$ de solução de pancreatina $(16,1 \mathrm{mg} / \mathrm{ml}$, em tampão fosfato $0,1 \mathrm{M})$ ou $0,25 \mathrm{ml}$ do tampão para os tubos dos brancos das amostras e incubados por mais 24 horas. Após as 24 horas de incubação a reação foi interrompida pela adição de $1,5 \mathrm{ml}$ de TCA $60 \%$ (concentração final $=10 \%$ ) e os tubos foram centrifugados $(7000 \mathrm{~g} / 15 \mathrm{~min})$. Após a centrifugação os sobrenadantes foram filtrados e ajustados em seus volumes para $25 \mathrm{ml}$ em balão volumétrico.

A porcentagem de hidrólise de cada amostra foi quantificada determinando-se o material solúvel no sobrenadante dos digeridos após precipitação com ácido tricloroacético (TCA) 10\% através de reação com reagente OPA (orto-ftaldialdeído), conforme descrito por Church et al. (1983) adicionando-se diretamente às alíquotas de $0-130 \mu \mathrm{l}$ de amostra $1 \mathrm{ml}$ de reagente OPA, diariamente preparado $(37,5 \mathrm{ml}$ de tetraborato de sódio $100 \mathrm{nM}$, 2,5 $\mathrm{ml}$ de do decilssulfato de sódio $20 \%, 60$ mg de OPA em 1,5 ml de metanol, $150 \mu \mathrm{l}$ de $\beta$-mercaptoetanol, volume final de $75 \mathrm{ml}$ ajustados com água destilada). Após exatos 2 minutos de reação as absorvâncias foram lidas a $340 \mathrm{~nm}$ contra branco da reação.

Uma curva analítica do aminoácido L-leucina, como referência, foi preparada e os resultados de grau de hidrólise calculados como a porcentagem de aminoácidos livres no sobrenadante, expressa como $\mu$ moles de L-leucina, em comparação ao total de $\mu$ moles de aminoácidos presentes nos $25 \mathrm{mg}$ de cada amostra, estimando-se com base no peso molecular médio dos aminoácidos (PM =113), de acordo com a seguinte fórmula:

$$
\% \mathrm{H}=\frac{\text { Aas }- \text { Aaba }- \text { Aabe }}{\text { Aatm }}
$$

onde:

Aas $=$ moles de aminoácidos determinados no sobrenadante da amostra

Aaba $=$ moles de aminoácidos determinados no sobrenadante do branco da amostra

Aabe $=$ moles de aminoácidos determinados no sobrenadante do branco das enzimas

Aatm $=$ moles totais de aminoácidos na amostra considerando-se o peso molecular médio dos aminoácidos (1 mol de aminoácidos $=113 \mathrm{~g}$ ).

\section{RESULTADOS E DISCUSSÃO}

\section{Composição proteica}

Foi realizada a análise da quantificação de proteína de cada amostra. A comparação do resultado desta análise com os rótulos dos produtos estão descritos na Tabela 1 . 
Tabela 1 - Teor de proteína das amostras de whey protein declarada nos rótulos e obtidas por análise da composição centesimal

\begin{tabular}{ccccc}
\hline Amostra & $\begin{array}{c}\text { Proteína } \\
\text { (análise } \\
\text { centesimal) } \\
(\%)\end{array}$ & $\begin{array}{c}\text { Proteína } \\
(\text { rótulo })\end{array}$ & $\begin{array}{c}\text { Variação entre } \\
\text { análise centesimal } \\
\text { e informação } \\
\text { do rótulo }\end{array}$ & $\begin{array}{c}\text { Conformidade } \\
\text { Anvisa* }\end{array}$ \\
\hline Amostra A & 78,1 & 90,0 & 11,9 & Adequado \\
Amostra B & 26,1 & 81,7 & 55,6 & Inadequado \\
Amostra C & 76,4 & 77,4 & 0,9 & Adequado \\
Amostra D & 53,7 & 60,0 & 6,3 & Adequado \\
Amostra E & 77,7 & 78,9 & 1,3 & Adequado \\
Amostra F & 78,9 & 88,7 & 9,8 & Adequado \\
Amostra G & 10,4 & 10,6 & 0,2 & Adequado \\
Amostra H & 56,1 & 64,3 & 8,2 & Adequado \\
Amostra I & 62,9 & 66,7 & 3,7 & Adequado \\
Amostra J & 72,7 & 70,0 & $-2,7$ & Adequado \\
Amostra K & 11,0 & 62,5 & 51,5 & Inadequado \\
Amostra L & 68,4 & 72,5 & 4,1 & Adequado \\
Amostra M & 85,1 & 61,1 & $-23,9$ & Adequado \\
\hline
\end{tabular}

* Fonte: ANVISA, 2003.

Na tabela acima, pode-se observar que das 12 amostras analisadas somente em 2 (duas) o teor de proteína encontrado na análise centesimal está muito discrepante da quantidade descrita no rótulo do produto. Em relação aos suplementos proteicos, a legislação vigente preconiza que o produto pronto para consumo deve conter, no mínimo, $10 \mathrm{~g}$ de proteína na porção e um limite de variação de $20 \%$ para mais ou para menos nas quantidades descritas no rótulo (ANVISA, 2003). Entretanto, existe ainda, uma deficiência de uma legislação rigorosa em relação aos suplementos alimentares, falta de fiscalização periódica destes produtos e limites de variação mais estreitos em relação aos produtos certificados pela Agência Nacional de Vigilância Sanitária (ANVISA, 2003) que hoje admite uma variação de $20 \%$ frente ao descrito no rótulo (SANTOS; SANTOS, 2002).

Ao comparar os resultados da análise centesimal com os valores expressos nos rótulos, a maioria das amostras encontravase em concordância com a legislação atual, conforme preconiza a ANVISA (ANVISA, 2003). Como já mencionado, observou-se que, na maioria dos casos, houve uma pequena diferença em relação ao teor de proteína encontrado na análise centesimal das amostras quando comparado ao rótulo dos produtos. No caso das duas amostras em que o valor da análise diferiu expressivamente do valor do rótulo deve ser levado em consideração alguns possíveis fatores que podem interferir na análise dos resultados, entre eles estão: a quantidade de amostras, o controle de matéria-prima (que pode ser inadequada para o uso na fabricação), o tipo de processamento industrial adotado, condições de estocagem, procedimentos no controle de qualidade, o lote do produto, entre outros (OLIVEIRA et al., 2015). 


\section{Digestibilidade proteica in vitro}

Foi realizada a análise da digestibilidade proteica in vitro por meio da medida do percentual de hidrólise de cada amostra de whey protein comercializados no município de Alfenas - MG, porém as amostras G, H e M não apresentaram resultado, pois foram descartadas devido a petrificação e com isso não foi possível utilizá-las na pesquisa. Os resultados estão descritos na Tabela 2 .

Tabela 2 - Digestibilidade proteica in vitro das amostras de whey protein

\begin{tabular}{c|c}
\hline Amostra & $\begin{array}{c}\text { Digestibilidade } \\
\text { (média } \pm \text { desvio padrão) }\end{array}$ \\
\hline Amostra A & $28,1 \pm 1,8$ \\
Amostra B & $31,1 \pm 2,2$ \\
Amostra C & $42,2 \pm 1,9$ \\
Amostra D & $31,8 \pm 3,0$ \\
Amostra E & $38,68 \pm 2,4$ \\
Amostra F & $38,1 \pm 2,2$ \\
Amostra G & - \\
Amostra H & - \\
Amostra I & $36,7 \pm 2,3$ \\
Amostra J & $38,6 \pm 3,9$ \\
Amostra K & $24,2 \pm 0,7$ \\
Amostra L & $38,6 \pm 3,5$ \\
Amostra M & - \\
Caseína (padrão) & $48,9 \pm 5,9$ \\
\hline
\end{tabular}

A digestibilidade é a porcentagem de proteínas que é hidrolisada pelas enzimas digestivas e absorvida pelo organismo, portanto, está ligada à qualidade do whey protein (MECHI et al., 2005). Em alguns estudos que seguem a mesma linha de pesquisa (digestibilidade proteica in vitro), tendo por base a caseína que é considera uma proteína de alto valor biológico como proteína padrão, encontrou-se valores de percentual de hidrólise proteica que variaram de $32,8 \%$ à $55,9 \%$ (MANTOANI et al., 2013; TAVANO et al.,
2004). Observando a tabela acima se pode constatar que os porcentuais de hidrólise das amostras oscilaram entre $24,2 \%$ e $42,2 \%$, ou seja, encontraram-se abaixo do valor de hidrólise proteica da caseína (adotada como proteína padrão). Sendo assim, podese sugerir que as amostras de whey protein analisadas apresentaram uma digestibilidade proteica relativamente boa.

No estudo de Souza et al. (2006), os autores verificaram o prejuízo no aproveitamento de proteínas de leite, quando este foi utilizado como fonte proteica em multimisturas, por causa da presença de fatores antinutricionais no produto. A presença de fatores antinutricionais nas amostras pode colaborar para que se justifiquem os baixos valores de digestibilidade proteica (MANTOANI et al., 2013).

Algumas pesquisas sobre a digestibilidade proteica in vitro de grãos, demonstraram que os grãos que sofreram algum tipo de processamento térmico apresentaram um porcentual de hidrólise proteica maior do que aqueles grãos que não sofreram algum tipo de processamento térmico (CASTRO et al., 2007).

Sabe-se que o calor é responsável pelo aumento da digestibilidade, pela inativação de alguns fatores antinutricionais, como inibidores de proteases. Os inibidores de proteases são substâncias de natureza proteica, presentes naturalmente em alguns alimentos, que interferem na atividade de sistemas enzimáticos do trato digestório, inibindo especialmente proteases, que são enzimas que hidrolisam as ligações peptídicas como primeiro passo para a assimilação das proteínas. Portanto, o tratamento térmico moderado em proteínas pode ser benéfico (CASTRO et al., 2007).

\section{CONCLUSÕES}

O estudo dos reais teores proteicos, em comparação ao declarado no rótulo, e 
mesmo o grau de hidrólise alcançado destas formulações, como indicativo de suas digestibilidades, se mostra cada vez mais importante. Em alguns casos verifica-se a presença de proteínas de baixo valor biológico, muitas vezes acompanhadas de fatores antinutricionais. A falta de fidedignidade nas declarações contidas nos rótulos quanto ao teor de proteínas de alto valor biológico como as do soro do leite (que tornam o produto mais caro) sinaliza para a necessidade de fiscalização constante.

\section{REFERÊNCIAS}

AKESON, W. R.; StAHMAN, M. A. A. Pepsin-pancreatin digest index of protein quality evaluation. Journal of Nutrition, v. 83, p. 257-61, 1964.

AGÊNCIA NACIONAL DE VIGILÂNCIA SANITÁRIA (ANVISA). Resolução de Diretoria Colegiada, $\mathrm{RDC} \mathrm{n}^{\circ} 18$, de 27 de abril de 2010. Aprova o Regulamento Técnico o Regulamento Técnico sobre Alimentos para Atletas. Diário Oficial da República Federativa do Brasil, 28 abr. 2010.

\section{AGÊNCIA NACIONAL DE VIGILÂNCIA} SANITÁRIA (ANVISA). Resolução de Diretoria Colegiada, $\mathrm{RDC} \mathrm{n}^{\circ} 360$, de 23 de dezembro de 2003. Aprova o Regulamento Técnico sobre Rotulagem Nutricional de Alimentos Embalados. Diário Oficial da República Federativa do Brasil, 2003.

AOAC. Official Methods of Analysis. Association of Official Analytical Chemists. $15^{\mathrm{a}}$ ed. Washington, D.C., 1990.

BRASIL. MINISTÉRIO DA AGRICULTURA, PECUÁRIA E ABASTECIMENTO. Instrução Normativa $n^{\circ} 16$, de 23 de agosto de 2005. Aprova o regulamento técnico de identidade e qualidade de bebida láctea. Diário Oficial da União, Brasília, 24 de agosto de 2005.
BRAVO, L. Polyphenols: Chemistry, Dietary Sources, Metabolism, and Nutritional Significance. Nutrition Reviews, v. 56, n. 11, p 317-333. 1998.

CASTRO, L. I. A. et al. Quinoa (Chenopodium Quinoa Willd): digestibilidade in vitro, desenvolvimento e análise sensorial de preparações destinadas a pacientes celíacos. Alimentos e Nutrição, v. 18, n. 4, Araraquara. 2007.

CHURCH, F.C. et al. Spectrophotometric assay using o-phthaldialdehyde for determination of proteolysis in milk and isolated milk proteins. Journal of Dairy Science, n. 66, p. 1219-1227, 1983.

HARAGUSHI, F. K. et al. Proteínas do soro de leite: composição, propriedades nutricionais, aplicações no esporte e benefícios para a saúde humana. Revista de Nutrição, v. 19, n. 4, 2006.

LACROIX, M. et al. Compared with casein or total milk protein, digestion of milk soluble proteins is too rapid to sustain the anabolic postprandial amino acid requirement. American Journal of Clinical Nutrition, v. 84, p. 1070-1079, 2006.

LOVATO, F. et al. Avaliação da conformidade de suplementos alimentares frente à legislação vigente. Revista Brasileira de Nutrição Esportiva, v. 8, n. 47, 2014.

MANTOANI, A. C. et al. Digestibilidade e antinutricionais em mix de cereais. Nutrire, v. 38, n. 3, p. 245-255, São Paulo. 2013.

MECHI, R. et al. Avaliação química, nutricional e fatores antinutricionais do feijão preto (Phaseolus vulgaris 1.) Irradiado. Ciência e Tecnologia de Alimentos, v. 25, n. 1,2005 . 
OSTE, R. E. Digestibility of processed food protein. Nutritional and Toxicological Consequences of Food Processing, p. 371$388,1991$.

OLIVEIRA, L. C. B. P. et al. Análise centesimal e comparativa de suplementos de proteínas do soro do leite bovino: whey protein. Revista Brasileira de Nutrição Esportiva, v. 9, n. 51, 2015.

RAWEL, H. M.et al. Model studies on reactions of plant phenols with whey proteins. Nahrung, v. 45, n. 2, p. 72-81. 2001.

RICHARDS, N. S. P. S. Soro lácteo: perspectivas industriais e proteção ao meio ambiente. Revista Food Ingredients, v. 38, n. 17, p. 20-27. 2002.

SANTOS, M. A. A.; SANTOS, R. P. Uso de suplementos alimentares como forma de melhorar a performance nos programas de atividade física em academias de ginástica. Revista Paulista de Educação Física, v. 16, n. 2, 2014.

SGARBIERI, V. C. Propriedades fisiológicas funcionais das proteínas do soro do leite. Revista de Nutrição, v. 17, n. 4, 2004.

SMITHERS, G. W. Whey and whey protein from 'gutter-to-gold'. Internation al Dairy Journal, v. 18, p. 695-704. 2008.

SOUZA, J. C. et al. Qualidade proteica de multimisturas distribuídas em Alfenas, Minas Gerais, Brasil. Revista de Nutrição, v. 19, p. 685-692, 2006.

TAVANO, O. L. et al. Nutritional evaluation of chickpea protein: microbiological and chemical methods. Alimentos e Nutrição, v. 15, n. 1, p. 17-22, Araraquara. 2004. 